\title{
Systematic review: the impact of exercise on mesenteric blood flow and its implication for preoperative rehabilitation
}

\author{
K. A. Knight ${ }^{1}$ - S. J. Moug ${ }^{2} \cdot$ M. A. West ${ }^{3}$
}

Received: 27 November 2016/ Accepted: 11 January 2017/Published online: 27 February 2017

(c) The Author(s) 2017. This article is published with open access at Springerlink.com

\begin{abstract}
Background Exercise in the preoperative period, or prehabilitation, continues to evolve as an important tool in optimising patients awaiting major intra-abdominal surgery. It has been shown to reduce rates of post-operative morbidity and length of hospital stay. The mechanism by which this is achieved remains poorly understood. Adaptations in mesenteric flow in response to exercise may play a role in improving post-operative recovery by reducing rates of ileus and anastomotic leak.

Aims To systematically review the existing literature to clarify the impact of exercise on mesenteric arterial blood flow using Doppler ultrasound.

Methods PubMed, EMBASE and the Cochrane library were systematically searched to identify clinical trials using Doppler ultrasound to investigate the effect of exercise on flow through the superior mesenteric artery (SMA). Data were extracted including participant characteristics, frequency, intensity, timing and type of exercise and the effect on SMA flow. The quality of each study was assessed using the Downs and Black checklist.

Results Sixteen studies, comprising 305 participants in total, were included. Methodological quality was generally poor. Healthy volunteers were used in twelve studies. SMA
\end{abstract}

M. A. West

M.West@soton.ac.uk

1 Department of Surgery, Queen Elizabeth University Hospital, 1345 Govan Road, Glasgow G51 4TF, UK

2 Department of Surgery, Royal Alexandra Hospital NHS Trust, Corsebar Road, Paisley PA2 2PN, UK

3 Academic Unit of Cancer Sciences, Faculty of Medicine, University of Southampton, South Block, Mail Point 816, Southampton University Hospital, Southampton SO16 6YD, UK flow was found to be reduced in response to exercise in twelve studies, increased in one and unchanged in two studies. Clinical heterogeneity precluded a meta-analysis. Conclusion The weight of evidence suggests that superior mesenteric arterial flow is reduced immediately following exercise. Differences in frequency, intensity, timing and type of exercise make a consensus difficult. Further studies are warranted to provide a definitive understanding of the impact of exercise on mesenteric flow.

Keywords Colorectal - Cancer - Mesenteric blood flow * Prehabilitation

\section{Introduction}

The systemic benefits of exercise have been recorded in the literature from as early as the time of Hippocrates [1]. Despite an acknowledgement throughout the centuries that exercise was necessary for the maintenance of health, it took until the twenty-first century for the idea that exercise can prevent disease to be formalised. In the 60 years that have elapsed since Morris and colleagues produced their landmark work "Coronary heart disease and physical activity of work" [2], which described lower rates of heart disease among physically active workers, strides have been undertaken in the use of exercise as preventative medicine. This is evidenced in the development of rehabilitation programmes following cardiac events which aim to reduce the likelihood of further events while returning patients to their baseline [3].

It has, however, taken somewhat longer for exercise to be recognised as a therapeutic tool which can be utilised as part of preoperative patient optimisation. General improvements arising from regular exercise including increases in muscle bulk, bone mineral density and strength 
are used in management of conditions such as osteoporosis $[4,5]$. The cardiovascular adaptations resulting from regular aerobic exercise are also exploited as part of the spectrum of treatment options for hypertension, diabetes, cardio- and cerebrovascular disease and obesity [6-10].

More recently, use of exercise prior to an acute stressor such as surgery has emerged as a viable perioperative riskreduction strategy $[11,12]$. This concept, known as prehabilitation, was first used in sports medicine to reduce the impact of an injury prior to its occurrence. It has been explored as a method of preoperative optimisation in patients undergoing elective intra-abdominal surgery, most often major cancer resection [13-16]. These patients also frequently undergo pre- or post-operative chemoradiotherapy. Prehabilitation has been used to successfully mitigate the negative effects on physical fitness induced by such treatments $[17,18]$. It is evolving to become a key part in the preoperative process for patients undergoing elective surgery $[14,16]$ and has been shown to aid return to baseline functioning [19], with further studies in progress examining its effect on post-operative outcomes.

The mechanistic link between physical exercise and improved outcome following colorectal surgery is yet to be fully elucidated. The changes occurring in the cardiorespiratory system in response to exercise have been studied in detail in a variety of training regimes [20-22]. The effect of exercise on mesenteric perfusion has been the subject of investigative research for over 60 years. However, the definitive impact of exercise, whether it be whole body involving large muscle groups or isometric involving specific muscles, on mesenteric blood flow continues to be a source of debate. Understanding the mechanisms by which preoperative exercise may improve outcome following colorectal surgery may in part lie in the response of the mesenteric vasculature. Bowel resection inevitably involves sacrificing a mesenteric vessel. If exercise improves mesenteric blood flow, it is conceivable that patients who exercise regularly may be less susceptible to complications following colorectal surgery such as delayed return of gut function, or even anastomotic breakdown.

The mesenteric circulation, comprising the superior and inferior mesenteric arteries arising directly from the abdominal aorta, is responsible for the delivery of arterial blood to the small bowel and colon. Multiple factors influence flow through these vessels, including central haemodynamics, autonomic stimulation and circulating hormones [23-25]. In athletes, the prevalence of lower gastrointestinal symptoms such as abdominal pain, diarrhoea and rectal bleeding suggests an alteration in flow during intense exercise [26, 27]. Other work has suggested that flow to the lower GI tract is preserved or even increased in the context of exercise [28-30].

The method of assessment of mesenteric haemodynamics has also varied over time, with invasive techniques involving cannulation of splanchnic vessels predominating in earlier years prior to the advent non-invasive imaging with Doppler ultrasonography. This improved the tolerability and feasibility of studies examining mesenteric flow. The aim of this systematic review was therefore to clarify the effects of exercise on the mesenteric circulation as assessed by Doppler ultrasound.

\section{Methods}

A systematic search of EMBASE, PubMed and Cochrane databases was performed with the assistance of a medical librarian. Clinical trials involving both healthy volunteers and patients using Doppler ultrasound to investigate the effect of exercise on superior mesenteric arterial (SMA) perfusion were included. The inferior mesenteric artery was not chosen as the target vessel due to difficulties in accurately identifying this on non-invasive imaging such as Doppler. Review articles which did not present original data were excluded. The hypothesis was that exercise improved SMA blood flow in healthy volunteers and patients when measured by Doppler ultrasonography, compared with flow at rest. The primary outcome was change in SMA flow in response to exercise.

\section{Search strategy}

PubMed (1950 to May 2015), EMBASE (1950 to May 2015) and Cochrane (1993 to May 2015) were searched using terms predefined by the reviewing authors (KK, MW). An update to the search using the same criteria was performed on 23 February 2016 in an attempt to capture any recently published literature. A hand search of the literature was conducted by the lead author using the reference lists of relevant original articles. Screening of each abstract was undertaken independently by two reviewers (KK, MW). Consensus was reached between reviewers on the suitability for inclusion. Full text versions of the included papers were then obtained and reviewed against the inclusion and exclusion criteria stated below. Both reviewers extracted the data from each included study using a predefined proforma.

\section{Inclusion criteria}

Those studies examining the effect of exercise on mesenteric blood flow in adults aged 18 or over were eligible for inclusion. Only studies utilising Doppler ultrasound for measurement of mesenteric flow were included. The target vessel had to be the superior mesenteric artery (SMA), avoiding confusion between the portal and mesenteric systems. 


\section{Exclusion criteria}

Studies using animals were not included. Those not written or available in the English language were also excluded, as were papers arising from expert opinion. The search was limited to papers published after 1945, when Doppler ultrasound was introduced to clinical practice.

\section{Data extraction and analysis}

The characteristics of each study, including the journal and country of publication, the study design and outcome measure, were extracted. The participant characteristics collected were type (healthy volunteer or patient), age, gender, height and weight. The primary outcome variable was SMA flow. The exercise outcome data extracted were: type, duration and intensity of exercise, pretest conditions, timing of measurements of SMA flow, flow parameter used and the effect on SMA perfusion. Meta-analyses were planned if sufficient clinical and statistical homogeneity was identified.

\section{Quality assessment}

The Downs and Black checklist [31] was used to assess the quality of each study. This tool scores articles over 5 domains (reporting, bias, confounding factors, external validity and power) to produce a numerical value out of a possible 30 points. The studies were scored independently by two authors (KK, MW), and discrepancies were resolved by discussion.

\section{Results}

\section{Data presentation and analysis}

"Appendix" details the search strategies across all three databases. The initial literature search produced 275 abstracts (225 PubMed, 49 EMBASE and 1 Cochrane). This is presented in Figure 1 as per the Preferred Reporting Items for Systematic Reviews and Meta-Analyses (PRISMA) guidelines. Ten duplicates were identified and subsequently removed. Two reviewers (KK, MW) independently screened all candidate abstracts. Eighteen full text reviews were undertaken, with two papers excluded at this stage, as they did not fulfil the inclusion criteria. Sixteen remained and were included in the review. It was not possible to perform a meta-analysis of the data due to statistical heterogeneity across the included studies.

\section{Included studies}

Sixteen studies, comprising 305 participants in total, were reviewed. Four studies enrolled patients, while twelve studies examined healthy volunteers. No restriction was placed on type of disease or exercise. The terms mesenteric and splanchnic are often used interchangeably when referring to colonic blood supply and were therefore included in the search strategy. All studies were single centre. There were no randomised controlled trials. The median number of patients in each was 12 .

\section{Quality assessment}

The Downs and Black checklist [31] was used to assess the quality of each included study. The median score, reflecting methodological quality, was 12 points. The study containing the most participants (59 triathletes) scored the highest at 19 points [32], while the paper scoring the least at 10 points is that widely cited as a seminal work in the study of mesenteric haemodynamics during exercise [28]. All of the included studies scored poorly in relation to power and internal validity due to confounding factors.

\section{Participant data}

One hundred and eighty-eight of 305 participants were male. It was not possible to determine the exact gender balance due to two studies in which gender was not stated, and a further study in which it was not clear due to exclusions. Twelve of sixteen studies recruited healthy volunteers. This ranged from untrained individuals to endurance athletes. One study examined patients with autonomic failure exclusively [33]. A further three studies compared patients with chronic disease to agematched controls: two examining the effects of exercise in patients with primary autonomic failure, and one study on patients with chronic heart failure [34-36]. Age range across the studies was variable. Study participants were significantly older in the trials where patients were recruited with a range from 46 to 72 years, while those recruiting healthy volunteers ranged in age from 20 to 51 years. Study and patient characteristics are summarised in Table 1.

\section{Type of exercise}

The characteristics of the exercise regimes employed in the studies varied widely in terms of frequency, intensity, timing and type. Table 2 describes the details of the exercise intervention used in each study. Cycling at a stated intensity (steady state exercise) for a predetermined duration was the exercise mode of choice for nine studies [28-30, 33, 34, 37-39, 44]. Treadmill exercise was used in two studies [36, 40]. Of the remaining studies, three examined mesenteric haemodynamics in response to isometric exercise [35, 41, 42], one study was based around a 


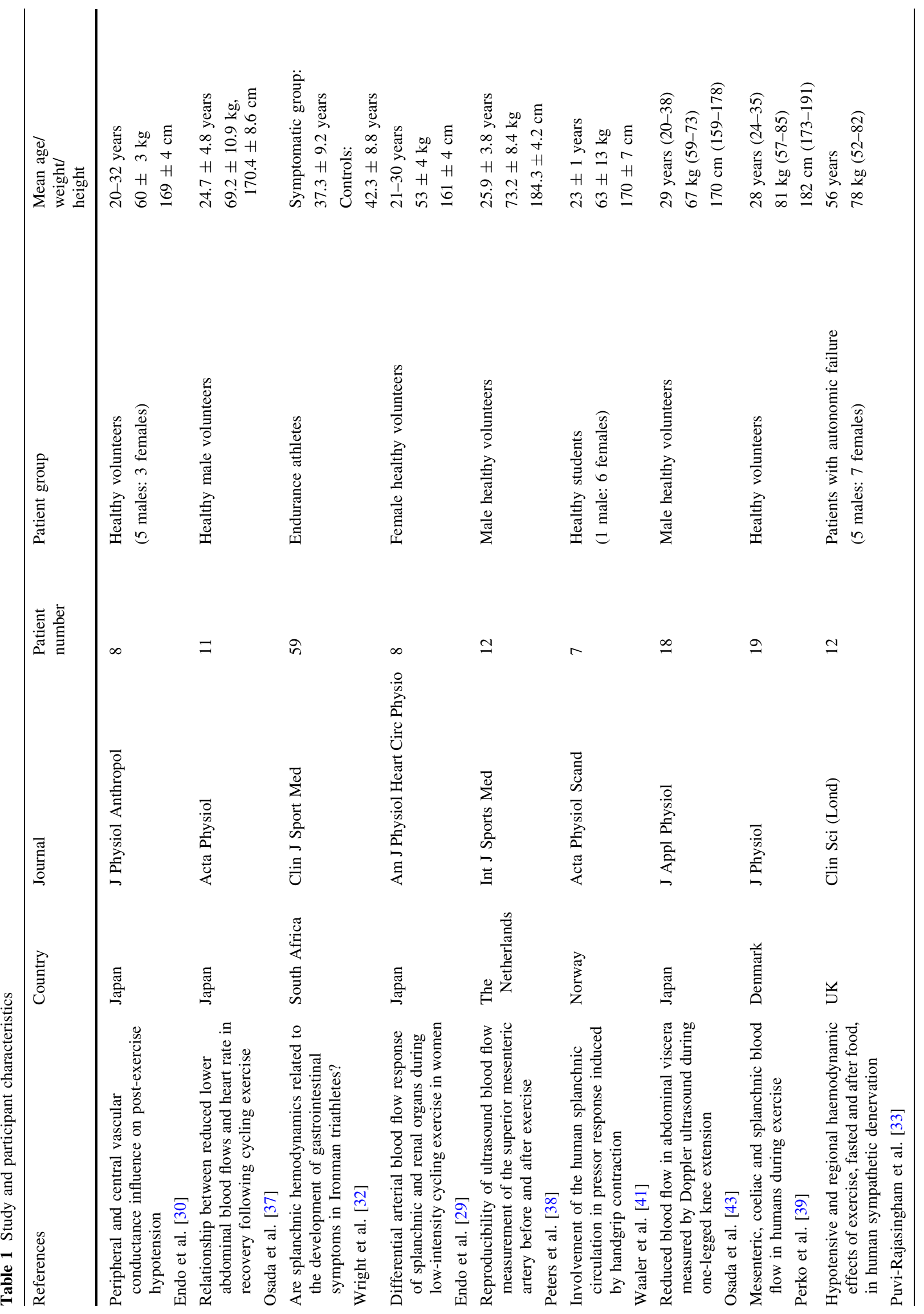




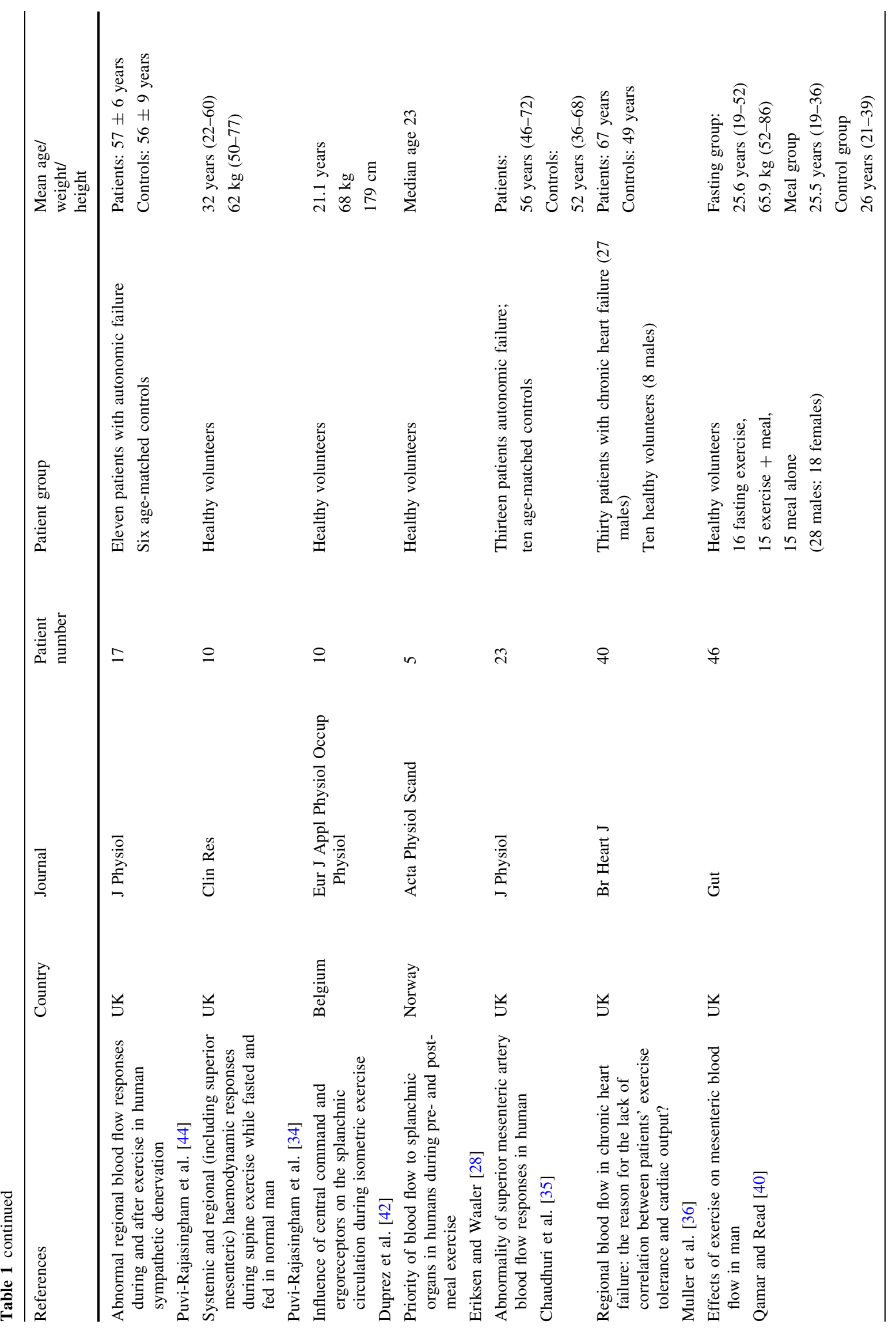


Table 2 Exercise intervention details according to the frequency, intensity, timing and type (FITT) principle

\begin{tabular}{|c|c|c|c|c|}
\hline References & Frequency & Intensity & Timing & Type \\
\hline Endo et al. [30] & Single episode & $60 \%$ of heart rate $(\mathrm{HR})$ reserve & $60 \mathrm{~min}$ & Ergometer cycling \\
\hline Osada et al. [37] & $\begin{array}{l}3 \times 12 \text { min session at different } \\
\text { target intensities }\end{array}$ & 30,50 and $85 \% \mathrm{VO}_{2} \max$ & $\begin{array}{l}3 \text { min each at } 1 / 3 \text { then } 2 / 3 \\
\max \text { intensity, } \\
6 \text { min at target intensity }\end{array}$ & Ergometer cycling \\
\hline Wright et al. [32] & - & - & - & $\begin{array}{l}\text { Triathlon: } \\
3.8 \mathrm{~km} \text { swim } \\
180 \mathrm{~km} \text { cycle } \\
42.2 \mathrm{~km} \text { run }\end{array}$ \\
\hline Endo et al. [29] & $\begin{array}{l}\times 3 \text { interspersed with } 30 \text { min rest } \\
\text { periods }\end{array}$ & $40 \mathrm{~W}$ & $4 \mathrm{~min}$ & Ergometer cycling \\
\hline Peters et al. [38] & $\begin{array}{l}\mathrm{x} 2 \text { interspersed with } 5 \mathrm{~min} \text { rest } \\
\text { period }\end{array}$ & $70 \% \mathrm{VO}_{2} \max$ & $30 \mathrm{~min}$ & Ergometer cycling \\
\hline Waaler et al. [41] & $\begin{array}{l}\text { x } 2 \text { pressor tests separated by } 10 \\
\text { min interval } \\
\text { Repeated after } 30 \text { min rest }\end{array}$ & $\begin{array}{l}40 \% \text { max voluntary } \\
\text { contraction }\end{array}$ & $2 \mathrm{~min}$ & Sustained handgrip \\
\hline Osada et al. [43] & Ten cycles per minute & $\begin{array}{l}\text { Low-intensity exercise (HR } \\
<90 \text { beats/min) }\end{array}$ & $20 \min$ & $\begin{array}{l}\text { Knee extension- } \\
\text { flexion }\end{array}$ \\
\hline Perko et al. [39] & Two episodes & $75 \% \mathrm{VO}_{2} \max$ & Not stated & $\begin{array}{l}\text { Fasting and } \\
\text { postprandial } \\
\text { ergometer cycling }\end{array}$ \\
\hline $\begin{array}{l}\text { Puvi-Rajasingham } \\
\text { et al. [33] }\end{array}$ & $\begin{array}{l}2 \times 9 \text { min session (fasting and } \\
\text { postprandial) }\end{array}$ & 25,50 and $75 \mathrm{~W}$ ( $3 \mathrm{~min}$ each) & $9 \min$ & Supine cycling \\
\hline $\begin{array}{l}\text { Puvi-Rajasingham } \\
\text { et al. [44] }\end{array}$ & Single session & 25,50 and $75 \mathrm{~W}$ ( 3 min each) & $9 \min$ & Supine cycling \\
\hline $\begin{array}{l}\text { Puvi-Rajasingham } \\
\text { et al. [34] }\end{array}$ & Two sessions separated by 2 days & 25,50 and $75 \mathrm{~W}$ ( 3 min each) & $9 \min$ & Ergometer cycling \\
\hline Duprez et al. [42] & Single episode & $\begin{array}{l}30 \% \text { maximal voluntary } \\
\text { contraction }\end{array}$ & $90 \mathrm{~s}$ & Ischaemic handgrip \\
\hline $\begin{array}{l}\text { Eriksen and Waaler } \\
\text { [28] }\end{array}$ & $\begin{array}{l}\text { Two sessions separated by } 8 \text { min } \\
\text { rest }\end{array}$ & $50-65 \mathrm{~W}$ and $150-200 \mathrm{~W}$ & 4 min each & Semi-supine cycling \\
\hline $\begin{array}{l}\text { Chaudhuri et al. } \\
\text { [35] }\end{array}$ & Single session & $1 / 3$ maximal pressure & $120 \mathrm{~s}$ & Isometric exercise \\
\hline Muller et al. [36] & Single session & $\begin{array}{l}2.7 \mathrm{~km} / \mathrm{h} \text { at varying slope } \\
\text { angles }(0,1.3,2.7)\end{array}$ & 4 min at each angle & $\begin{array}{l}\text { Submaximal } \\
\text { treadmill exercise }\end{array}$ \\
\hline $\begin{array}{l}\text { Qamar and Read } \\
\text { [40] }\end{array}$ & Single session & $5 \mathrm{~km} / \mathrm{h} 20 \%$ gradient & $15 \min$ & Walking (treadmill) \\
\hline
\end{tabular}

triathalon [32], and one examined the response to knee extension-flexion at a stated intensity [43].

The conditions in which the exercise was undertaken were also diverse (Table 3). In two studies, no pretest details were divulged [32, 37], but in the remaining studies the participants were required to fast. The duration of fasting ranged from $3 \mathrm{~h}$ pretest to $12 \mathrm{~h}$; seven studies stated that patients fasted overnight. A pretest supine rest was mandatory in seven studies with duration varying from 20 to $40 \mathrm{~min}$ across the studies. Two studies precluded exercise in the $24 \mathrm{~h}$ prior to testing, while the remaining seven studies did not state whether a pretest rest was undertaken.

\section{Effect of feeding}

In six studies, exercise was undertaken initially in fasting subjects then repeated following the ingestion of food [28, 33, 34, 39-41]. Meals were adjusted for size and energy content (1100-1700 kCal) depending on the participant's weight in two studies [28, 41], while a further three studies used commercially available liquid meals varying in energy content from 390-550 kCal [33, 34, 40]. Perko [39] gave a $1000 \mathrm{kCal}$ meal as standard. All studies included a $30 \mathrm{~min}$ rest period prior to undertaking exercise after meal ingestion. Both Waaler [41] and Perko [39] found that the reduction in SMA flow was less marked 


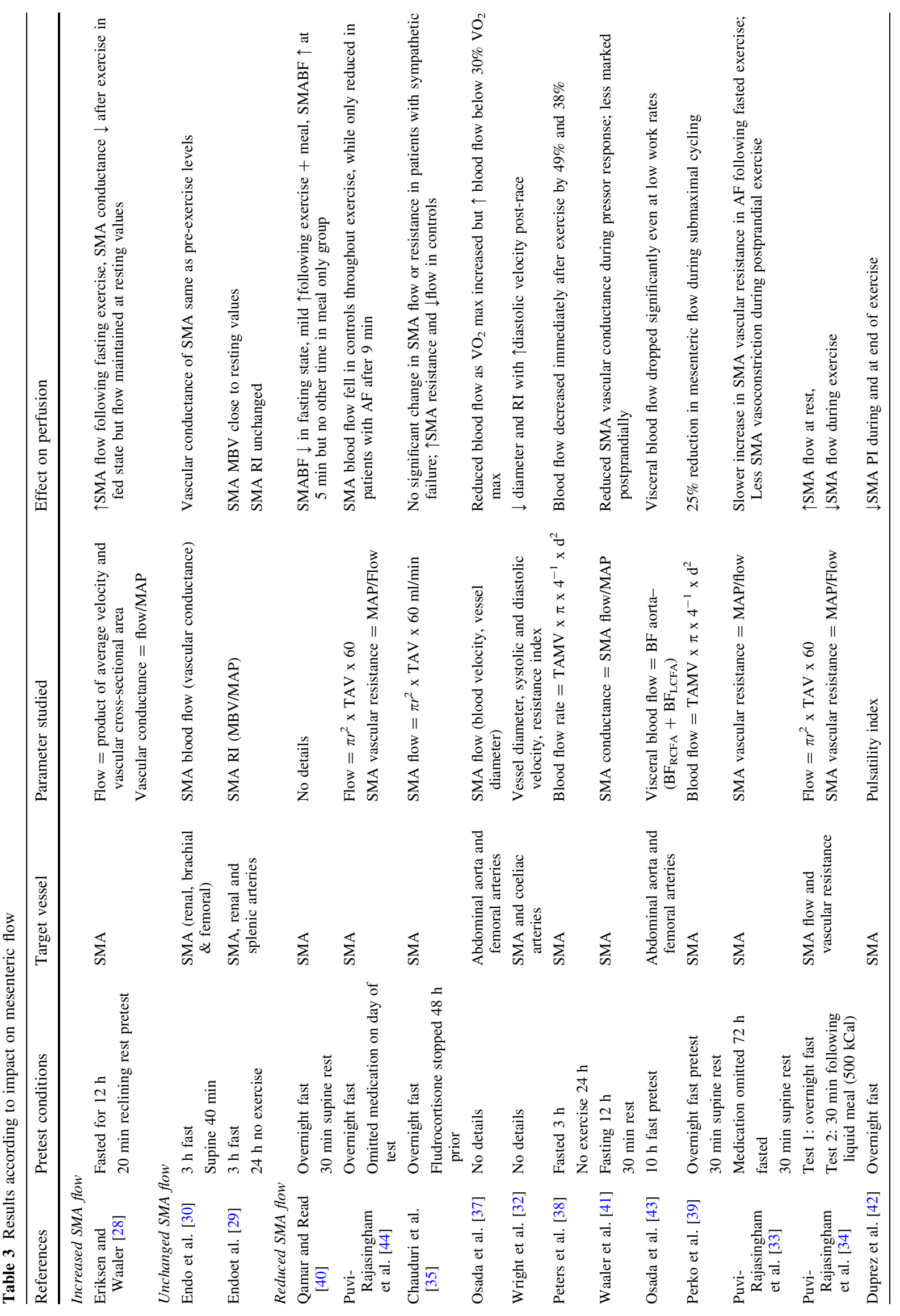


when exercising in the fed state compared with fasting. However, a further two studies, both conducted by the same group, found the opposite: SMA flow was reduced in exercise undertaken in both the fasting and fed state [33, 34]. Eriksen [28] found a moderate increase in SMA flow during exercise, but flow was unchanged in the fed state. Finally, Qamar reported a fall in SMA blood flow during exercise in the fasting state but an increase with exercise following meal ingestion [40].

\section{Assessment of perfusion}

Only studies using Doppler ultrasound to assess SMA haemodynamics were included. In two studies, the flow in the superior mesenteric artery was estimated by measuring blood flow in the aorta and both femoral arteries [37, 43]. Otherwise, the SMA was the target vessel. A variety of correlates of flow were used across the included articles: impedance, conductance, pulsatility index, velocity, vessel diameter and cross-sectional area. One study gave no details on the method of determination of SMA flow [40].

\section{Timing of assessment}

Muller [36] did not comment on the timing of the measurements of mesenteric flow in relation to the exercise performed. Across the remaining studies, the point in time where mesenteric flow was measured varied widely, ranging from 3 min following cessation of exercise to multiple measurements made over time extending up to $45 \mathrm{~min}$. The timing and frequency of assessments are outlined in Table 4.

\section{Effect on mesenteric perfusion}

Table 3 summarises the studies by impact on SMA flow. Muller [36] did not produce definitive data clarifying their findings of the effect of exercise on mesenteric perfusion. Twelve of the remaining fifteen studies found mesenteric perfusion to be lower during or following exercise [32-35, 37-44]. Higher levels than resting flow were noted in one study [28]. It was unchanged in two studies [29, 30].

\section{Discussion}

This systematic review sought to clarify the effect of exercise on flow through the superior mesenteric artery. Based on the available evidence, a definitive statement of the true impact of acute exercise on the mesenteric vasculature remains difficult. Basic exercise physiology favours the position that aerobic exercise results in reduced flow through the mesenteric arterial system in order to meet the demands of exercising muscle during and immediately after exercise. Exercising patients preoperatively can improve their physiological performance [13]. By exposing the SMA-dependent colon to acute reductions in flow, regular exercise may also condition the colon to situations such as surgical resection where flow will be reduced. The longer-term adaptations at cellular level in this setting are unknown, but increased ability to extract oxygen from the circulating arterial blood could be key to optimising anastomotic healing in patients undergoing colonic surgery.

The majority of the literature reviewed supports the theory that SMA flow is reduced in response to acute exercise. However, it remains unclear whether this is true for all types of exercise. The included studies used different intensities, durations and types of exercise with measurements made at varying intervals. This makes comparison of outcomes challenging. Therefore, a general consensus on the effect of exercise on mesenteric flow must be interpreted carefully in the context of these variables.

\section{Effect of intensity on SMA flow}

It has long been suggested that mesenteric blood flow is reduced in proportion to the intensity of exercise [45-47]. The prevalence of GI symptoms in endurance athletes supports this theory [48-50]. Intensity varied widely across the studies and was recorded in different ways. In studies of dynamic exercise, it was expressed as a function of $\mathrm{VO}_{2} \max$ [37-39], energy conversion in watts $[28,29,33,34,44]$ and as the speed and gradient of incline on walking [36, 40]. A further two studies related exercise intensity to heart rate, expressed as beats per minute [43] and percentage heart rate reserve [30]. In those involving isometric exercise [35, 41, 42], intensity was measured as a percentage of maximal voluntary contraction. These measurements are not directly interchangeable, and therefore, the relationship between intensity and SMA flow requires consideration of these variables.

The effect of exercise at different intensities on SMA flow was examined in five studies [28, 33, 34, 37, 44]. Puvi-Rajasingham [34] used the same protocol of graded exercise with increments of 25 watts in three studies, including healthy volunteers and patients with autonomic failure (AF) [33, 44]. It was not possible to take measurements during exercise in one study and post-exercise measurements taken at $2 \mathrm{~min}$ were used as a surrogate [33], producing results which could not be assessed in relation to increasing intensity. SMA blood flow was progressively reduced throughout the graded exercise protocol in controls in the study involving healthy volunteers [34] while only reduced at the highest intensity in patients with AF [44]. The lack of sympathetic stimulation in the latter group would explain this finding with slower change occurring due to cellular release of circulating chemical agents. 
Table 4 Timing of assessments of mesenteric flow

\begin{tabular}{|c|c|c|c|}
\hline Study & Pre-exercise assessment & Assessment during exercise & Post-exercise assessment \\
\hline Endo et al. [30] & $25-40 \mathrm{~min}$ & - & $\begin{array}{l}\text { Post 1: } 15-30 \mathrm{~min} \\
\text { Post 2: } 40-45 \mathrm{~min}\end{array}$ \\
\hline Osada et al. [37] & Time not stated & - & $\begin{array}{l}\text { Every } 45 \mathrm{~s} \text { until } 3 \mathrm{~min} \text {, alternate minutes between } \\
\quad 4-14 \mathrm{~min}\end{array}$ \\
\hline Wright et al. [32] & Up to 3 days prerace & - & Upon race completion \\
\hline Endo et al. [29] & Not stated & $\begin{array}{l}\text { Ten points in first } 2 \mathrm{~min} \text {; every } 30 \mathrm{~s} \text { for } \\
2 \mathrm{~min}\end{array}$ & Every $30 \mathrm{~s}$ for $3 \mathrm{~min}$ \\
\hline Peters et al. [38] & $\begin{array}{l}\text { Three times in } 25 \text { min rest } \\
\text { period }\end{array}$ & - & $\begin{array}{l}\text { Test } 1 \text { : immediately following } 30 \text { min cycling } \\
\text { Test } 2 \text { : following } 20 \text { min cycling }\end{array}$ \\
\hline Waaler et al. [41] & $2 \mathrm{~min}$ intervals for $5 \mathrm{~min}$ & During last $20 \mathrm{~s}$ of $2 \mathrm{~min}$ test & $2 \mathrm{~min}$ intervals for $5 \mathrm{~min}$ \\
\hline Osada et al. [43] & One resting measurement & Every $5 \mathrm{~min}$ for $20 \mathrm{~min}$ & At $1 \mathrm{~min}$, between 2 and $5 \mathrm{~min}$ \\
\hline Perko et al. [39] & One resting measurement & One measurement during exercise & 2 min after cycling \\
\hline $\begin{array}{l}\text { Puvi-Rajasingham et al. } \\
\text { [44] }\end{array}$ & Time not specified & At 3,6 and $9 \mathrm{~min}$ & At 2,5 and $10 \mathrm{~min}$ \\
\hline $\begin{array}{l}\text { Puvi-Rajasingham et al. } \\
\text { [33] }\end{array}$ & Time not specified & At 3,6 and $9 \mathrm{~min}$ & At 2,5 and $10 \mathrm{~min}$ \\
\hline $\begin{array}{l}\text { Puvi-Rajasingham et al. } \\
\text { [34] }\end{array}$ & Time not specified & At 3,6 and $9 \mathrm{~min}$ & At 2,5 and $10 \mathrm{~min}$ \\
\hline Duprez et al. [42] & Continuously $3 \mathrm{~min}$ & Continuously for $90 \mathrm{~s}$ & Continuously for $3 \mathrm{~min}$ \\
\hline Eriksen et al. [28] & $\begin{array}{l}\text { During final } 2 \mathrm{~min} \text { of } 20 \mathrm{~min} \\
\text { rest }\end{array}$ & $\begin{array}{l}\text { During the final } 2 \mathrm{~min} \text { at end of } 4 \mathrm{~min} \\
\text { cycle }\end{array}$ & During final $2 \mathrm{~min}$ of $8 \mathrm{~min}$ rest period \\
\hline Chauduri et al. [35] & 10 min prior & At $120 \mathrm{~s}$ & - \\
\hline Muller et al. [36] & - & - & - \\
\hline Qamar et al. [40] & After 30 min rest & - & $T=0,5,10,15,30 \mathrm{~min}$ \\
\hline
\end{tabular}

$A F$ autonomic failure, $B P$ blood pressure, $C O$ cardiac output, $M A P$ mean arterial pressure, $M B V$ mean blood volume, $L C F A$ left common femoral artery, $R C F A$ right common femoral artery, $R I$ resistance index, $S M A$ superior mesenteric artery, $S M A B F$ superior mesenteric artery blood flow, $S V R$ systemic vascular resistance, TAMV time-averaged mean velocity, TAV time-averaged velocity, USS ultrasound

Osada [37] found a similar trend in mesenteric haemodynamics when measuring abdominal blood flow in response to $12 \mathrm{~min}$ of ergometer cycling in healthy volunteers. At $30 \% \mathrm{VO}_{2} \mathrm{max}$, blood flow was slightly increased, while at $50 \% \mathrm{VO}_{2} \max$ it was reduced by one-third and at $85 \% \mathrm{VO}_{2} \max$ by $89 \%$. Blood flow in this study was calculated by subtracting flow in the proximal right femoral artery from that in the abdominal aorta superior to the coeliac axis. While this indirect measure of mesenteric flow produces an estimation of SMA flow in contrast with other more direct measures, the results are similar, demonstrating clearly the compensatory decrease in SMA flow to facilitate redistribution of cardiac output as intensity rose.

The increase, although small, in flow at low-intensity contrasts with the moderate increases in SMA flow recorded in Eriksen's study of semi-supine cycling at 50-65 and 150-200 W [28]. Measurements of SMA flow were taken in both the fasting and fed state. While exercise induced an increase in splanchnic vascular resistance and thereby reduced vascular conductance, it was not sufficient to reduce SMA flow. This was true in the fasted and postprandial state. The authors attributed their novel findings to the direct method of SMA flow measurement, the brief duration of exercise $(4 \mathrm{~min})$ and the submaximal intensity of exercise. Exercise of similar intensities was utilised in several studies [37-39], all of which found SMA flow to be reduced. Duration of exercise was indeed more prolonged in these studies, ranging from 12 to $30 \mathrm{~min}$. Two studies also used direct measurement of the SMA to provide flow rates [38,39]. The reproducibility of Eriksen's findings has not been established in a study using similar duration, intensity and type of exercise. It remains a finding of note but contrasts with the body of evidence supporting decreased flow during exercise [32-34, 37-43].

On balance, the evidence suggests that flow through the SMA is reduced as exercise intensity increases. The findings of Eriksen and Waaler suggest that this may not be uniformly applicable, but the mechanism of increased SMA flow in response to exercise remains a finding which requires further studies of similar methodology to validate.

\section{Type of exercise}

Table 2 demonstrates the different types of exercise used. Twelve employed dynamic exercise [28-30, 32-34, 36-40, 44], three isometric exercise [35, 41, 42] and one resistance exercise [43]. Dynamic exercise has been discussed in detail above, and therefore, here isometric and resistance exercise is examined.

The effect of sympathoneural activation during isometric exercise on mesenteric flow was examined in three 
studies [35, 41, 42]. Isometric exercise produces a sudden and significant cardiovascular stress [51]. In contrast to dynamic exercise, isometric exercise co-activates vagal and sympathetic responses [37]. Mean arterial pressure, cardiac output and heart rate increase as isometric contractile force increases [52]. Weipert suggested that isometric contractions may trigger a stronger chemoreflex response due to metabolite accumulation which raises blood pressure via sympathetic vasoconstriction [53].

Chauduri [35], Waaler [41] and Duprez [42] reported a reduction in SMA blood flow in response to sustained submaximal handgrip. Intensity in Duprez's [42] and Chauduri's [35] experiments was set at 30\% maximum voluntary contraction, while Waaler [41] used 40\% MVC. At intensities between 40 and $60 \%$ MVC, blood flow within the isometrically-contracting muscle reduces significantly or ceases completely, resulting in greater accumulation of metabolites to activate chemoreceptors. Duration was shorter at $90 \mathrm{~s}$ in Duprez's study but similar in the others at $120 \mathrm{~s}$ [35, 41]. Chauduri included patients with autonomic failure alongside age-matched controls [35]. SMA blood flow was unchanged in the patient group, most probably due to a lack of vasoconstrictor nerve activity, while SMA constriction occurred during isometric exercise in healthy volunteers; the constriction therefore was likely to have been mediated neurally. Duprez found that the pulsatility index of the SMA was reduced in response to isometric exercise, translating to splanchnic vasodilatation, while Waaler noted vascular conductance to fall secondary to SMA vasoconstriction. Overall, the effect of isometric exercise on mesenteric flow was mediated by sympathetic nerve activity and found to be uniformly reduced.

Osada [43] examined blood flow in response to knee extension-flexion exercise against loads corresponding to increasing intensities of $2.1,5.4,10.3$ and $15.2 \mathrm{~W}$ over a 20 min period. Reduced visceral blood flow was recorded, despite exercise intensity not being sufficient to raise the heart rate above 90 beats per minute. At heart rates of less than $90 \mathrm{bpm}$, the role of circulating catecholamines in mediating vasoconstriction is likely minimal, as demonstrated by Breuer [54]. Resistance exercise causes pronounced increases in both systolic and diastolic blood pressure resulting from sympathetic vasoconstriction, mechanical compression of blood vessels within the exercising muscle and the Valsalva manoeuvre generated [55]. The metabolite-induced vasodilatation within muscle stimulates group IV afferents, while group III afferents are excited by the mechanical distortion [56]. Low levels of dynamic exercise have been shown to activate group III and IV afferent fibres [57]. This in turn maintains cardiac output at a level sufficient to maintain the elevated blood pressure required to perfuse the dynamically exercising muscle [58]. There is a paucity of data examining the mechanism between the chemo- and mechanorececeptor reflex and its impact on regional flow, particularly with regard to the mesenteric circulation. No other studies were identified which used resistance exercise while examining flow. However, low-intensity dynamic exercise in women was found to result in unchanged rather than reduced flow [29]. Whether the mechanism resulting in suppression of SMA flow in exercise utilising isolated muscle groups differs from that in more generalised dynamic exercise remains to be elucidated and indeed validated by other studies.

\section{Timing of measurements}

It is known that adaptations in the splanchnic circulation are most pronounced in the early phase of exercise [59]. The precise timing of measurements of SMA flow therefore has significant bearing on the result given the minute-tominute variation in central and splanchnic haemodynamics. It is worth noting, particularly with regard to those studies making limited measurements, that these were static measurements of dynamic processes. Thus, having multiple points of assessment throughout exercise and the period thereafter produces a trend that enables interpretation of the changes occurring throughout.

Measurements were taken at various intervals across the studies (Table 4). Both studies which found SMA flow to be unchanged following exercise contrasted in the time points chosen for assessment, despite originating from the same authors [29, 30]. Endo [30] recorded measurements between 15 and $30 \mathrm{~min}$ and again at approximately $40 \mathrm{~min}$ following $60 \mathrm{~min}$ of ergometer cycling. Subjects were resting in the supine position during this time. The delay between cessation of exercise and measurement of SMA flow means that haemodynamics in the immediate period following exercise are not captured. The resulting data are likely to reflect recovery of the splanchnic circulation following exercise rather than adaptations in the acute phase. Endo [29] also measured the resistance index of the SMA in response to 4 min of ergometer cycling in a separate study. Measurements were taken at 14 points during exercise and at 6 points in the first 3 min following exercise. The findings were similar: the resistance index of the SMA was essentially unchanged. These studies contrast both in their methodology and in the timing and calculation of SMA flow, with the former using indirect measures (Table 1). The consistency of the finding of unchanged flow does suggest that timing alone cannot explain this. The much shorter duration of exercise coupled with the low intensity in the latter study could contribute to this finding, while the former study's late measurements could explain the perceived lack of change in mesenteric haemodynamics.

Isometric exercise lends itself more easily to frequent measurements due to its static nature. Duprez [42] obtained measurements continuously before, during and after exercise. Waaler [41] measured SMA conductance at $2 \mathrm{~min}$ 
intervals during the pre- and post-exercise period and obtained a single measurement during exercise. Chauduri [35] took measurements before and immediately upon cessation of $120 \mathrm{~s}$ of isometric exercise. Across these three studies, SMA flow was reduced in healthy volunteers, regardless of method of measurement. While the timing of measurement is only one variable influencing the interpretation of SMA flow data, the recording of flow correlates throughout the exercise period and thereafter produces a trend which supports the consensus that in isometric exercise, SMA flow falls.

Of sixteen studies, only one (Eriksen [28]) reported increased SMA flow during exercise. Flow was measured before, during and after exercise consisting of semi-supine cycling at 50-65 and 150-200 $\mathrm{W}$ for 4 min each. Interestingly, their finding of increased SMA flow following exercise in the fasting state is to our knowledge unique. This has not been previously recorded in fasting exercise, only in postprandial exercise [41]. This study was small, with only five participants. Measurements were taken in the final 2 min of the resting, exercise and recovery phases (Table 4). SMA conductance fell during exercise in the postprandial state, but flow rates were maintained at pre-exercise levels despite this. The authors suggested the short duration of exercise and submaximal intensity may account for their findings. Other studies of similar exercise duration included Osada [37], Endo [29] and Muller [36] (Table 3). Intensity varied across these three studies. Endo [29] reported unchanged flow and Osada [37] found flow to be reduced, while Muller produced data for SMA blood flow at rest only. The significant heterogeneity in methodology and results renders interpretation of the physiological mechanism underlying Eriksen's finding of increased flow almost impossible. Further studies would be required of similar intensity, duration and type of exercise to validate this.

\section{Special circumstances: fasting and postprandial exercise}

Meal ingestion is known to be a potent splanchnic arterial vasodilator in humans [60] and results in a notable reduction in the superior mesenteric artery pulsatility index [61]. Six studies examined splanchnic haemodynamics in response to exercise in the fasting and fed state [28, 33, 34, 39-41]. Meal composition was tailored to individual size and weight in two studies [28, 41], while the others used commercially available liquid meals. Energy content varied from 390 to $1700 \mathrm{kCal}$ across the studies. Qamar [40] gave a liquid meal during the first $10 \mathrm{~min}$ of exercise. Otherwise, meals were given at 30 min pre-exercise. Aside from Eriksen's study [28], all uniformly found SMA flow to be reduced by exercise. Qamar [40] reported a temporary and modest increase in flow at $5 \mathrm{~min}$ following postprandial exercise. Flow was found to be more profoundly suppressed in fasting exercise, with less of a reduction noted postprandially $[33,34,39,41]$. It can be presumed on the basis of these data that exercise in the fed state confers the benefit of postprandial vasodilation that protects against the increased mesenteric vascular tone induced by exercise. Digestioninduced vasodilatation is likely to result from the combined effects of local hormones [39], sympathetic stimulation [34] and meal load. When combined with exercise, these studies support the theory that exercise has little or no effect on SMA resistance in the postprandial state.

\section{Strengths and weaknesses of the systematic review}

This article provides a contemporary review of the literature to date examining the effect of exercise on flow through the superior mesenteric artery. It was conducted in a systematic and rigorous fashion to ensure all relevant articles were identified. Using two investigators to screen each abstract and eligible full text paper against predefined criteria minimised bias. Using the SMA as the target vessel ensured distinction from the portal venous system which has also been studied in relation to exercise but does not solely give information on the blood supply to the bowel.

There were, however, limitations. All studies included were small $(n<60)$ and single centre, bringing into question both internal and external validity. Methodological quality was also poor overall. Twelve of sixteen studies were also conducted more than 15 years ago, suggesting waning interest in this important area. Well-designed, randomised controlled trials examining both the effect of acute exercise and regular exercise training on the mesenteric circulation are required to provide an up-to-date consensus, which will go some way to helping us understand and exploit the use of exercise in the preoperative period.

\section{Conclusion}

The literature on the impact of exercise on mesenteric flow in man spans more than four decades and encompasses various frequencies, intensities, timings and types. A variety of different methods of assessment have been and continue to be used, with Doppler ultrasound remaining a reliable and convenient method of non-invasive assessment. It is at times difficult to perform accurate Doppler studies during exercise due to breathing artefact, particularly at higher workloads. More recently, magnetic resonance imaging of the splanchnic system is evolving to produce very detailed and accurate estimations of flow. Taking into account the heterogeneity observed across the studies in this review, a unifying statement is difficult. However, the majority of evidence supports the consensus that superior mesenteric arterial flow is reduced sacrificially and diverted to other areas during exercise. This 
process is less marked in the circumstance of exercise following ingestion of diet. As always, further studies of robust methodology would serve to improve the basis of this consensus.

The potential for longer-term adaptations in mesenteric flow in response to exercise training also presents an area requiring further exploration. Preoperative exercise has been shown to improve cardiorespiratory function [13, 62]. It is likely to confer change in other vascular beds, including the mesenteric arterial system. Preconditioning the mesenteric vasculature to the low flow states which may be encountered both during and after surgery for colonic resection through the use of exercise may reduce the risk of impaired anastomotic blood supply and subsequent healing. Studies examining mesenteric haemodynamics in response to regular exercise are therefore key to understanding the impact and potential utilisation of preoperative exercise in patients undergoing surgery which disrupts the normal mesenteric arterial supply.

Acknowledgements The initial literature search was performed by Steven Kerr, Librarian, Royal College of Surgeons Edinburgh, in June 2015. A second literature search carried out in February 2016 using the same search strategy was conducted by Seona Hamilton, Specialist Librarian, NHS Greater Glasgow and Clyde.
Author's contribution Katrina Knight is the guarantor of article. KK and MW contributed to conceptualisation. KK and MW contributed to data extraction. KK, MW and SM contributed to analysis. MW and SM supervised the article. KK and MW contributed to original draft. KK, MW and SM contributed to review and editing. All authors reviewed and approved the final version of this article prior to submission.

\section{Compliance with ethical standards}

Conflict of interest The authors have no interests to declare.

Ethical approval This article does not contain any studies with human participants or animals performed by any of the authors.

Informed consent For this type of study formal consent is not required.

Open Access This article is distributed under the terms of the Creative Commons Attribution 4.0 International License (http://creative commons.org/licenses/by/4.0/), which permits unrestricted use, distribution, and reproduction in any medium, provided you give appropriate credit to the original author(s) and the source, provide a link to the Creative Commons license, and indicate if changes were made.

\section{Appendix}

See Tables 5 and 6.

Table 5 Pubmed literature review search conducted on 24.02.16

\begin{tabular}{|c|c|c|}
\hline No. & Query & Expected results \\
\hline$\# 1$ & $\begin{array}{l}\text { Hemodynamic* [tiab] OR Haemodynamic* [tiab] OR (blood [tiab] AND } \\
\text { velocity* [tiab]) OR (blood* [tiab] AND flow* [tiab]) }\end{array}$ & 332,083 \\
\hline \#2 & $\begin{array}{l}\text { Exercis* [tiab] OR (physical* [tiab] AND fitness [tiab]) OR (physical* [tiab] } \\
\text { AND extert* [tiab]) OR (physical* [tiab] AND fit* [tiab]) }\end{array}$ & 227,879 \\
\hline \#3 & Doppler [tiab] & 85,215 \\
\hline \#4 & (Splanchni* [tiab] OR mesenter* [tiab]) & 57,027 \\
\hline \#5 & (\#1 AND \#2 AND \#3 AND \#4) & 33 \\
\hline \#6 & $\begin{array}{l}\text { "Exercise" [Mesh] OR "Exercise Therapy"[Mesh] OR "Physical } \\
\text { Exertion" [Mesh] OR "Physical Fitness"[Mesh] }\end{array}$ & 206,385 \\
\hline \#7 & $\begin{array}{l}\text { "Hemodynamics”[Mesh] OR “Blood Flow Velocity”[Mesh] OR "Regional } \\
\text { Blood Flow”[Mesh] }\end{array}$ & 610,249 \\
\hline \#8 & “Splanchnic Circulation”[Mesh] OR “Mesenteric Arteries”[Mesh] & 28,105 \\
\hline \#9 & "Ultrasonography, Doppler”[Mesh] & 57,969 \\
\hline \#10 & (\#6 AND \#7 AND \#8 AND \#9) & 8 \\
\hline \#11 & $8,036,905$ [uid] & 1 \\
\hline \#12 & $13,356,576$ [uid] & 1 \\
\hline \#13 & $3,596,339$ [uid] & 1 \\
\hline \#14 & $9,824,727$ [uid] & 1 \\
\hline \#15 & Similar articles for PubMed (Select $8,036,905$ ) & 102 \\
\hline \#16 & Similar articles for PubMed (Select $13,356,576)$ & 101 \\
\hline \#17 & Similar articles for PubMed (Select 3,596,339) & 119 \\
\hline \#18 & Similar articles for PubMed (Select 9,824,727) & 106 \\
\hline \#19 & (\#15 OR \#16 OR \#17 OR \#18) & 343 \\
\hline \#20 & (\#5 OR \#10) NOT \#19 & 23 \\
\hline \#21 & (\#5 OR \#10) NOT \#19 Filters: English & 23 \\
\hline \#22 & \#19 Filters: Humans; English & 204 \\
\hline \#23 & \#22 OR \#21 & 227 \\
\hline
\end{tabular}




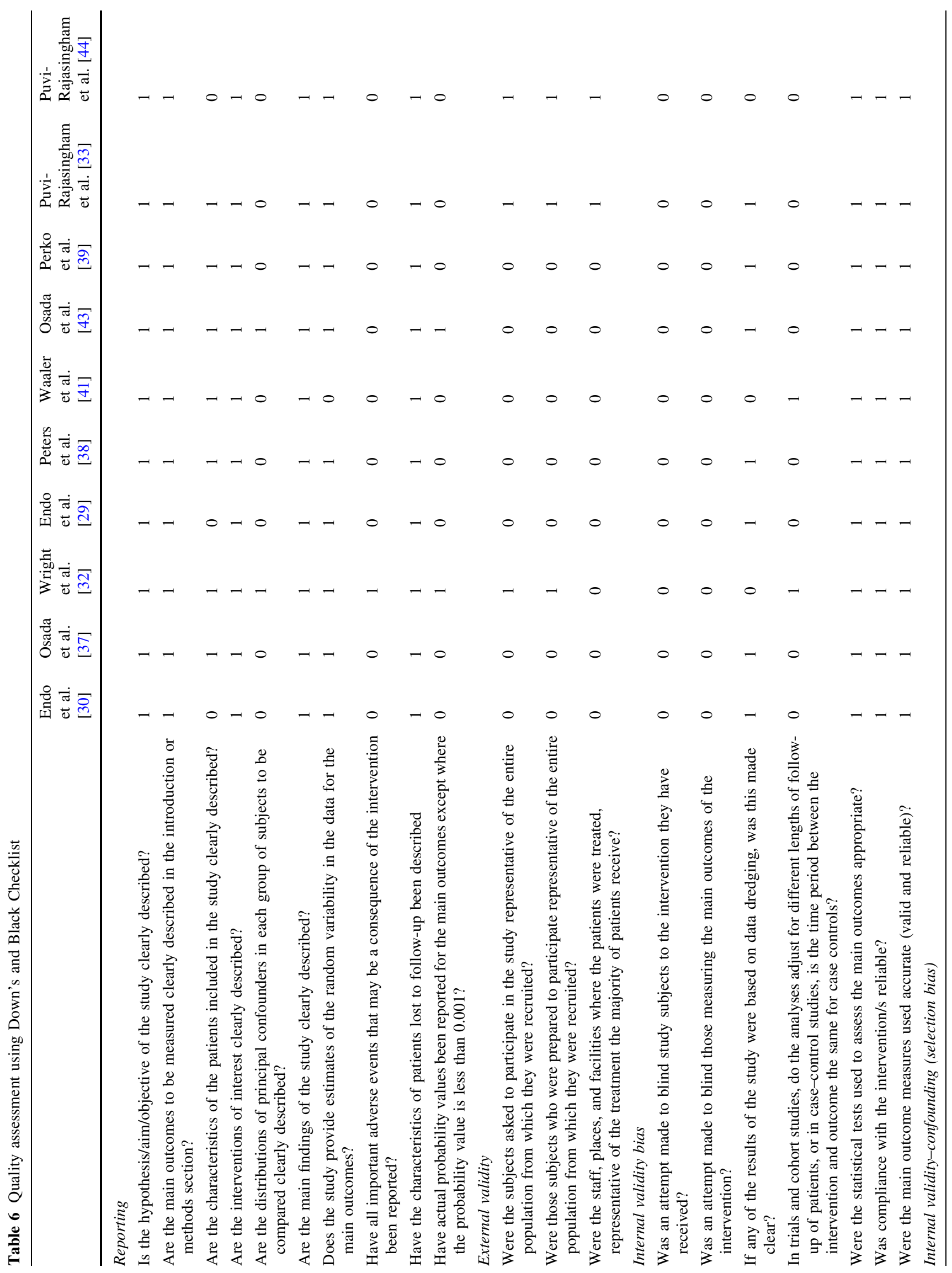




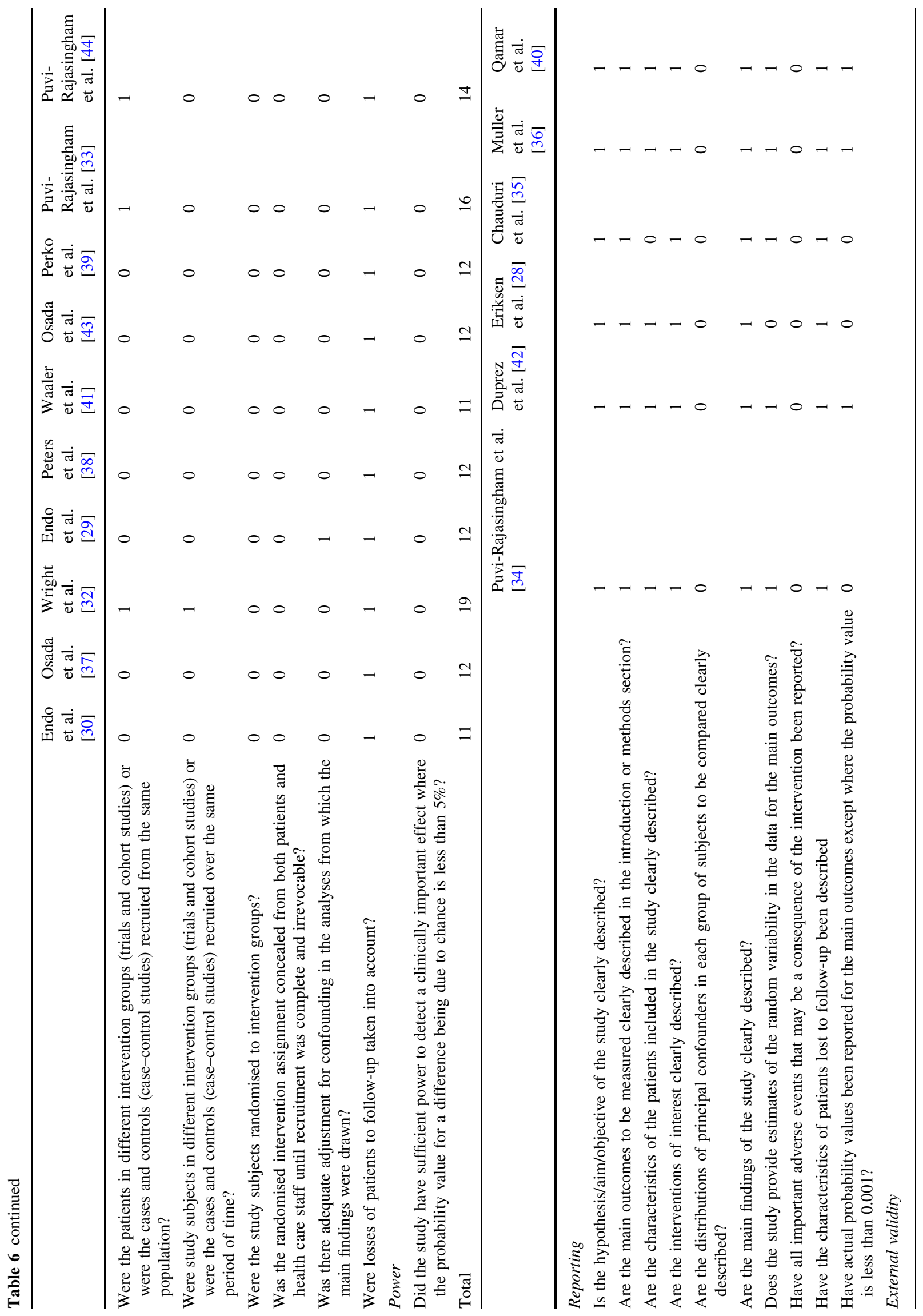




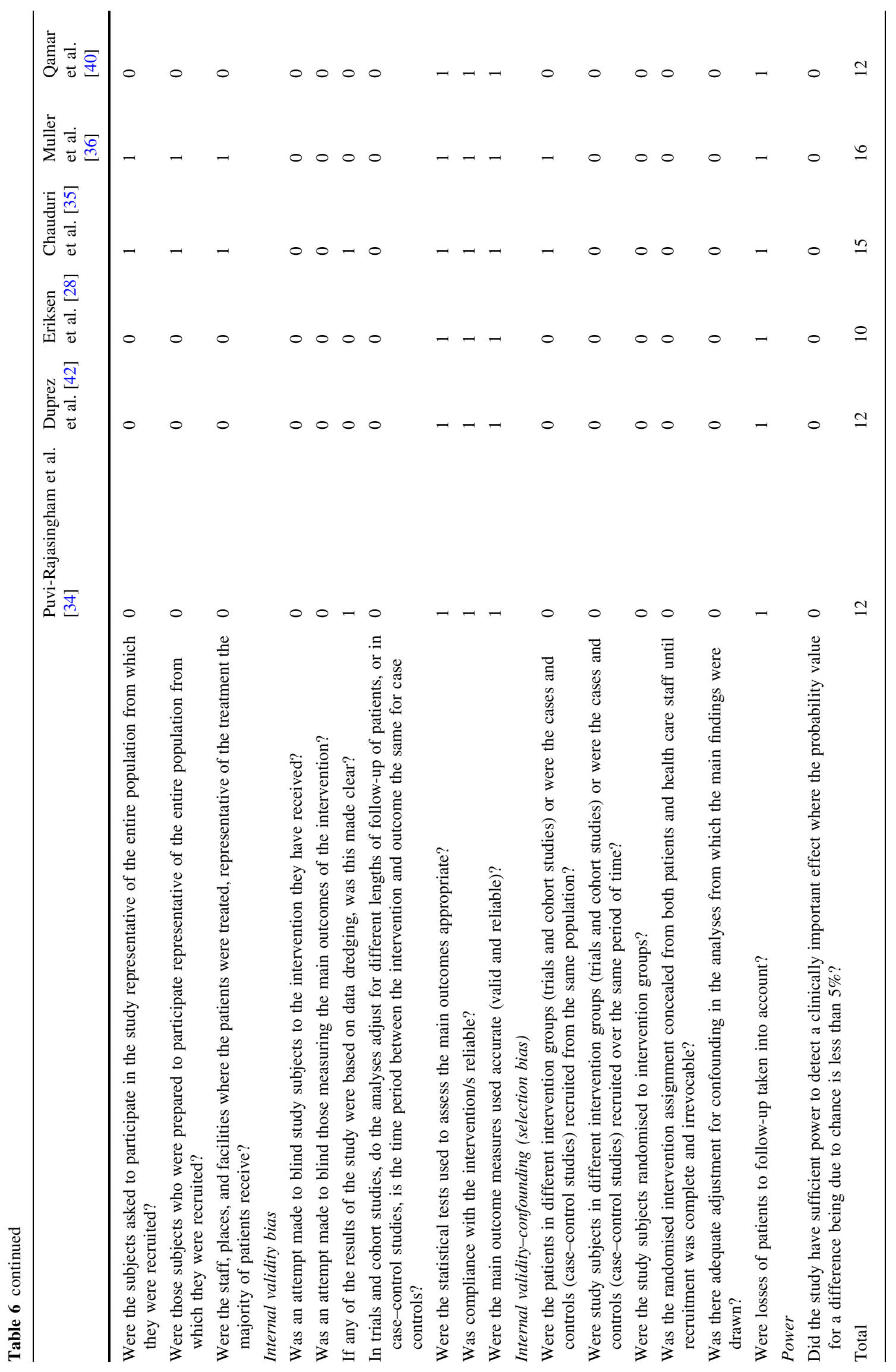




\section{References}

1. Jones WHS (1953) Hippocrates. Hippocrates: with an english translation by W. H. S. Jones. William Heinemann, London

2. Morris JN, Heady JA, Raffle PAB, Roberts CG, Parks JW (1953) Coronary heart disease and physical activity of work. Lancet 262(6795): 1053-1057

3. Leon AS, Franklin BA, Costa F, Balady GJ, Berra KA, Stewart KJ, Thompson PD, Williams MA, Lauer MS (2005) AHA scientific statement: cardiac rehabilitation and secondary prevention of coronary heart disease. Circulation 111:369-376

4. Bonaiuti D, Shea B, Iovine R, Negrini S, Robinson V, Kemper HC, Wells G, Tugwell P, Cranney A (2002) Exercise for preventing and treating osteoporosis in postmenopausal women. Cochrane Database Syst Rev 3:CD000333

5. Howe TE, Shea B, Dawson LJ, Downie F, Murray A, Ross C, Harbour RT, Caldwell LM, Creed G (2011) Exercise for preventing and treating osteoporosis in postmenopausal women. Cochrane Database Syst Rev. 7:CD000333

6. Pescatello LS, Franklin BA, Fagard R, Farquhar WB, Kelley GA, Ray CA (2004) American College of Sports Medicine. American College of Sports Medicine position stand. Exercise and hypertension. Med Sci Sports Exerc 36(3):533-553

7. Kraus WE, Houmard JA, Duscha BD, Knetzger KJ, Wharton MB, McCartney JS, Bales CW, Henes S, Samsa GP, Otvos JD, Kulkarni KR, Slentz CA (2002) Effects of the amount and intensity of exercise on plasma lipoproteins. N Engl J Med 347(19):1483-1492

8. Pan XR, Li GW, Hu YH et al (1997) Effects of diet and exercise in preventing NIDDM in people with impaired glucose tolerance. The Da Qing IGT and Diabetes Study. Diabetes Care 20:537-544

9. Lindström J, Ilanne-Parikka P, Peltonen M et al (2006) (the Finnish Diabetes Prevention Study Group). Sustained reduction in the incidence of type 2 diabetes by lifestyle intervention: follow-up of the Finnish Diabetes Prevention Study. Lancet 368:1673-1679

10. Shaw KA, Gennat HC, O'Rourke P, Del Mar C (2006) Exercise for overweight or obesity. Cochrane Database Syst Rev 4:003817

11. Pearse RM, Holt PJ, Grocott MP (2011) Managing perioperative risk in patients undergoing elective non-cardiac surgery. Br Med J 343:d5759

12. Jack S, West M, Grocott MP (2011) Perioperative exercise training in elderly subjects. Best Pract Res Clin Anaesthesiol 25(3):461-472

13. O'Doherty AF, West M, Jack S, Grocott MP (2013) Preoperative aerobic exercise training in elective intra-cavity surgery: a systematic review. Br J Anaesth 110(5):679-689

14. Boereboom CL, Williams JP, Leighton P, Lund JN (2015) Exercise prehabilitation in colorectal cancer Delphi study group Forming a consensus opinion on exercise prehabilitation in elderly colorectal cancer patients: a Delphi study. Tech Coloproctol 19(6):347-354

15. Gillis C, Li C, Lee L, Awasthi R, Augustin B, Gamsa A, Liberman AS, Stein B, Charlebois P, Feldman LS, Carli F (2014) Prehabilitation versus rehabilitation: a randomized control trial in patients undergoing colorectal resection for cancer. Anesthesiol 121(5):937-947

16. Cheema FN, Abraham NS, Berger DH, Albo D, Taffet GE, Naik AD (2011) Novel approaches to perioperative assessment and intervention may improve long-term outcomes after colorectal cancer resection in older adults. Ann Surg 253(5):867-874

17. Loughney L, West MA, Kemp GJ, Grocott MP, Jack S (2015) Exercise intervention in people with cancer undergoing adjuvant cancer treatment following surgery: a systematic review. Eur $\mathbf{J}$ Surg Oncol 41(12):1590-1602
18. Loughney L, West MA, Kemp GJ, Grocott MP, Jack S (2016) Exercise intervention in people with cancer undergoing neoadjuvant cancer treatment and surgery: a systematic review. Eur J Surg Oncol 42(1):28-38

19. West MA, Loughney L, Lythgoe D, Barben CP, Sripadam R, Kemp GJ, Grocott MP, Jack S (2015) Effect of prehabilitation on objectively measured physical fitness after neoadjuvant treatment in preoperative rectal cancer patients: a blinded interventional pilot study. Br J Anaesth 114(2):244-251

20. Gibala MJ, Little JP, MacDonald MJ, Hawley JA (2012) Physiological adaptations to low-volume, high-intensity interval training in health and disease. J Physiol 590:1077-1084

21. Goodwin GM, McCloskey DI, Mitchell JH (1972) Cardiovascular and respiratory responses to changes in central command during isometric exercise at constant muscle tension. J Physiol 226(1):173-190

22. Spina RJ, Ogawa T, Kohrt WM, Martin WH, Holloszy JO, Ehsani AA (1993) Differences in cardiovascular adaptations to endurance exercise training between older men and women. J App Physiol 75(2):849-855

23. Parks DA, Jacobson ED (1985) Physiology of the Splanchnic Circulation. Arch Intern Med 145(7):1278-1281

24. Steiner LA, Staender S, Sieber CC, Skarvan K (2007) Effects of simulated hypovolaemia on haemodynamics, left ventricular function, mesenteric blood flow and gastric $\mathrm{pCO}_{2}$. Acta Anaesthesiol Scand 51:143-150

25. Jodal M, Lundgren O (2011) Neurohormonal control of gastrointestinal blood flow. Compr Physiol. doi:10.1002/cphy. cp060146

26. Moses FM (1990) The effect of exercise on the gastrointestinal tract. Sports Med 9(3):159-172

27. terSteege RW, Kolkman JJ (2012) Review article: the pathophysiology and management of gastrointestinal symptoms during physical exercise, and the role of splanchnic blood flow. Aliment Pharmacol Ther 35(5):516-528

28. Eriksen M, Waaler BA (1994) Priority of blood flow to splanchnic organs in humans during pre- and post-meal exercise. Acta Physiol Scand 150(4):363-372

29. Endo MY, Suzuki R, Nagahata N, Hayashi N, Miura A, Koga S, Fukuba Y (2008) Differential arterial blood flow response of splanchnic and renal organs during low-intensity cycling exercise in women. Am J Physiol Heart Circ Physiol 294(5):H2322$\mathrm{H} 2326$

30. Endo MY, Shimada K, Miura A, Fukuba Y (2012) Peripheral and central vascular conductance influence on post-exercise hypotension. J Physiol Anthropol 18(31):32

31. Downs SH, Black N (1998) The feasibility of creating a checklist for the assessment of the methodological quality both of randomised and non-randomised studies of health care interventions. J Epidemiol Community Health 52:377-384

32. Wright H, Collins M, Villiers RD, Schwellnus MP (2011) Are splanchnic hemodynamics related to the development of gastrointestinal symptoms in Ironman triathletes? A prospective cohort study. Clin J Sport Med 21(4):337-343

33. Puvi-Rajasingham S, Smith GD, Akinola A, Mathias CJ (1998) Hypotensive and regional haemodynamic effects of exercise, fasted and after food, in human sympathetic denervation. Clin Sci (Lond) 94(1):49-55

34. Puvi-Rajasingham S, Wijeyekoon B, Natarajan P, Mathias CJ (1997) Systemic and regional (including superior mesenteric) haemodynamic responses during supine exercise while fasted and fed in normal man. Clin Auton Res 7(3):149-154

35. Chaudhuri KR, Thomaides T, Mathias CJ (1992) Abnormality of superior mesenteric artery blood flow responses in human sympathetic failure. J Physiol 457:477-489 
36. Muller AF, Batin P, Evans S, Hawkins M, Cowley AJ (1992) Regional blood flow in chronic heart failure: the reason for the lack of correlation between patients' exercise tolerance and cardiac output? Br Heart J 67(6):478-481

37. Osada T, Iwane H, Katsumura T, Murase N, Higuchi H, Sakamoto A, Hamaoka T, Shimomitsu T (2012) Relationship between reduced lower abdominal blood flows and heart rate in recovery following cycling exercise. Acta Physiol (Oxf) 204(3):344-353

38. Peters HP, de Leeuw D, Lapham RC, Bol E, Mosterd WL, de Vries WR (2001) Reproducibility of ultrasound blood flow measurement of the superior mesenteric artery before and after exercise. Int J Sports Med 22(4):245-249

39. Perko MJ, Nielsen HB, Skak C, Clemmesen JO, Schroeder TV, Secher NH (1998) Mesenteric, coeliac and splanchnic blood flow in humans during exercise. J Physiol 15(513):907-913

40. Qamar MI, Read AE (1987) Effects of exercise on mesenteric blood flow in man. Gut 28(5):583-587

41. Waaler BA, Toska K, Eriksen M (1999) Involvement of the human splanchnic circulation in pressor response induced by handgrip contraction. Acta Physiol Scand 166(2):131-136

42. Duprez D, Voet D, De Buyzere M, Drieghe B, Vyncke B, Mareels S, Afschrift M, Clement DL (1995) Influence of central command and ergoreceptors on the splanchnic circulation during isometric exercise. Eur J Appl Physiol Occup Physiol 71(5):459-463

43. Osada T, Katsumura T, Hamaoka T, Inoue S, Esaki K, Sakamoto A, Murase N, Kajiyama J, Shimomitsu T, Iwane H (1999) Reduced blood flow in abdominal viscera measured by Doppler ultrasound during one-legged knee extension. J Appl Physiol 86(2):709-719

44. Puvi-Rajasingham S, Smith GD, Akinola A, Mathias CJ (1997) Abnormal regional blood flow responses during and after exercise in human sympathetic denervation. J Physiol 505(Pt 3):841-849

45. Wade OL, Combes B, Chilos AW et al (1956) The effect of exercise on the splanchnic blood flow and splanchnic blood volume in normal men. Clin Sci 15(457):63

46. Rowell LB (1973) Regulation of splanchnic blood flow in man. Physiologist 16(2):127-142

47. Clausen JP (1977) Effect of physical training on cardiovascular adjustments to exercise in man. Physiol Rev 57(779):815

48. de Oliveira EP, Burini RC, Jeukendrup A (2014) Complaints during exercise: prevalence, etiology, and nutritional recommendations. Sports Med 44:79

49. Worobetz LJ, Gerrard DF (1985) Gastrointestinal symptoms during exercise in Enduro athletes: prevalence and speculations on the aetiology. N Z Med J 98:644-646
50. Riddoch C, Trinick T (1988) Gastrointestinal disturbances in marathon runners. Br J Sports Med 22:71-74

51. Fisher ML, Nutter DO, Jacobs W, Schlant RC (1973) Haemodynamic responses to isometric exercise in patients with heart disease. Br Heart J 35:422-432

52. Laughlin MH (1999) Cardiovascular response to exercise. Am J Physiol 277(6 Pt 2):S244-S259

53. Weippert M, Behrens K, Rieger A, Stoll R, Kreuzfeld S (2013) Heart rate variability and blood pressure during dynamic and static exercise at similar heart rate levels. PLoS ONE 8(12):e83690

54. Breuer HW, Skyschally A, Schulz R, Martin C, Wehr M, Heusch G (1993) Heart rate variability and circulating catecholamine concentrations during steady state exercise in healthy volunteers. Br Heart J 70(2):144-149

55. MacDonald JR (2002) Potential causes, mechanisms, and implications of post exercise hypotension. J Hum Hypertens 16(4):225-236

56. Nobrega ACL, O’Leary D, Silva BM, Marongiu E, Piepoli MF, Crisafulli A (2014) Neural Regulation of cardiovascular response to exercise: role of central command and peripheral afferents. BioMed Res Int 2014:478965

57. Adreani CM, Hill JM, Kaufman MP (1997) Responses of group III and IV muscle afferents to dynamic exercise. J Appl Physiol 82:1811-1817

58. Rowell LB (1985) O'Leary DS (1990) Reflex control of the circulation during exercise: chemoreflexes and mechanoreflexes. J Appl Physiol 69(2):407-418

59. van Wijck K, Lenaerts K, van Loon LJ, Peters WH, Buurman WA, Dejong CH (2011) Exercise-induced splanchnic hypoperfusion results in gut dysfunction in healthy men. PLoS ONE 6(7):e22366

60. Sabbá C, Eerraioli G, Genecin P et al (1991) Evaluation of postprandial hyperemia in superior mesenteric artery and portal vein in healthy and cirrhotic humans: an operator-blind echoDoppler study. Hepatology 13:714-718

61. Iwao T, Oho K, Nakano R, Yamawaki M, Sakai T, Sato M, Miyamoto Y, Toyonaga A, Tanikawa K (1998) Effect of meal induced splanchnic arterial vasodilatation on renal arterial haemodynamics in normal subjects and patients with cirrhosis. Gut 43:843-848

62. Sebio GR, Yáñez Brage MI, Giménez Moolhuyzen E, Granger CL, Denehy L (2016) Functional and postoperative outcomes after preoperative exercise training in patients with lung cancer: a systematic review and meta-analysis. Interact CardioVasc Thorac Surg 23(3):486-497 